\title{
COVID-19: Anticipating A Dramatic Collapse And A Recessionary Phase In The World Economy
}

\author{
Dr. Sandeep 0jha \\ Assistant Professor, Department of Business Administration \\ College of Applied Sciences, Salalah, Sultanate of Oman.
}

\author{
Ms. Shubha \\ B. A. LL.B. (Hons.) National \\ Law University, Jodhpur, Rajasthan
}

\begin{abstract}
The global nature of the pandemic, along with its great intensity and prolonged duration, will fundamentally alter the business landscape through changing trade flows, asset prices and consumption patterns. The outpouring of whammy 'Corona Bug' a public health crunch, an undetectable foe, jolted the attention of the world population towards the strictness that postured the economic vulnerability in almost all the macroeconomic variables such as GDP growth, headline inflation, unemployment rate, investment, current account balance and a measure of political risk which affected nook-n-corner of the world clock in terms of its demand-supply dynamic disruptions. This exploratory study is an attempt to explore the need of the efforts is to put in place a comprehensive action plan and put in the best efforts to implement the plan.
\end{abstract}

Key words: Pandemic, Corona, Economic, Macroeconomics, GDP

\section{INTRODUCTION}

Economy dwindles as the world faces humanity's biggest crisis since WWII- COVID-19! Across the world, almost every country is experiencing the wrath of the devastating Coronavirus disease (COVID-19). The epicentre of this outbreak has shifted from China to Europe and further to United States. Till date, over 1.5 million people have been affected by COVID-19 and about 80,000 people have succumbed to the deadly disease. Inevitably, this outbreak has developed as a stumbling block to economic growth. There are no precise measures that can be used to estimate and measure the level of impact of a growing pandemic on the scale of the forecasted decline in economic growth in the global economy and in the economies of individual countries.

WTO economists believe that it is likely that the economic decline will exceed the trade slump brought on by the global financial crisis of 2008-09. This is evident from the chart below (Figure 1). With almost equal uncertainty come the estimates of the expected recovery in 2021. The outcomes will largely depend on the duration of the outbreak and the effectiveness of the policy responses. A positive statement came forth from WTO Director General, Roberto Azevêdo when he said, 
Ojha, S., \& Shubha. (2020) COVID-19: Anticipating A Dramatic Collapse and A Recessionary Phase In The World Economy. Archives of Business Research, 8(5). 1-7.

"A rapid, vigorous rebound is possible. Decisions taken now will determine the future shape of the recovery and global growth prospects. We need to lay the foundations for a strong, sustained and socially inclusive recovery. Trade will be an important ingredient here, along with fiscal and monetary policy. Keeping markets open and predictable, as well as fostering a more generally favourable business environment, will be critical to spur the renewed investment we will need. And if countries work together, we will see a much faster recovery than if each country acts alone."

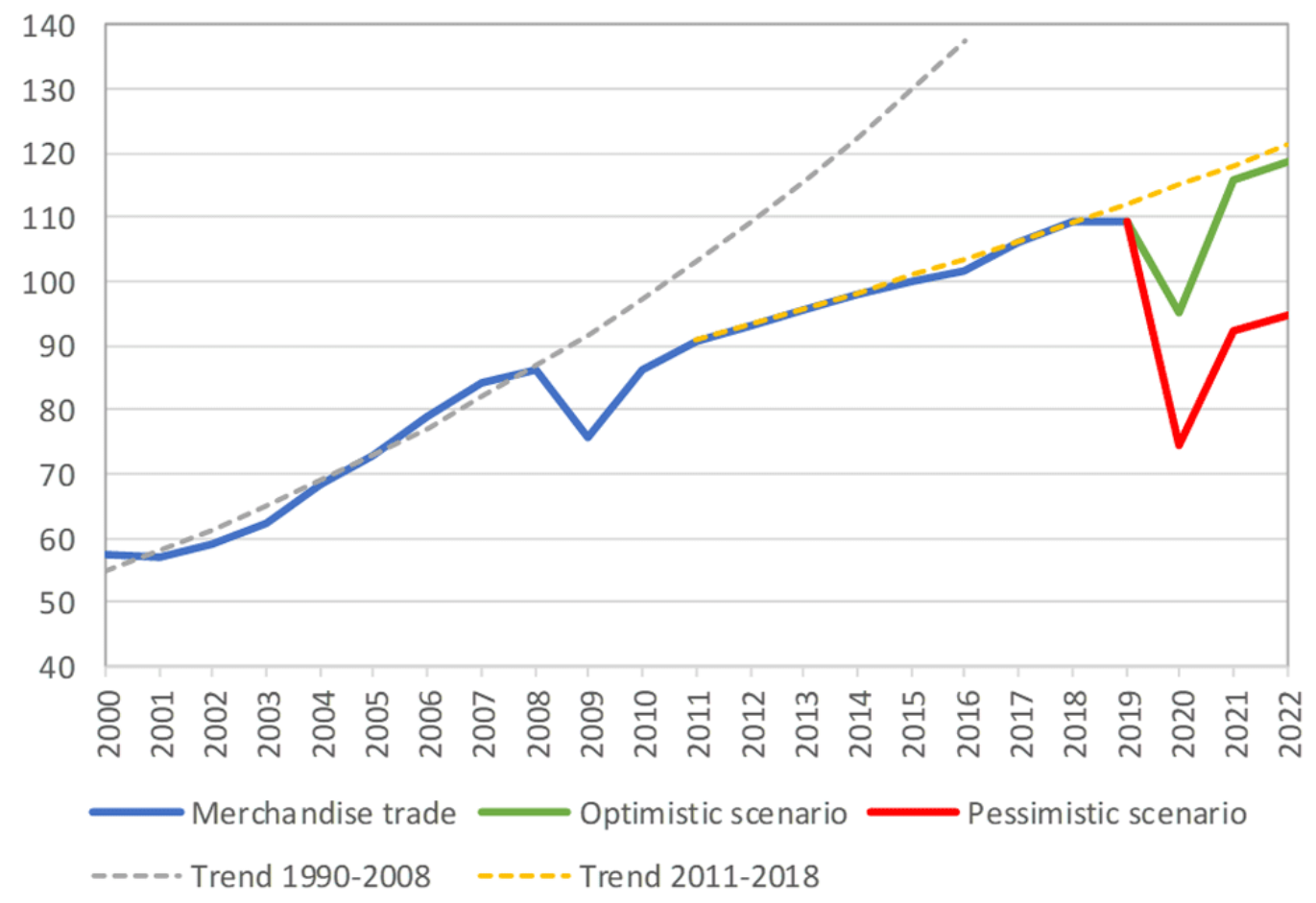

Figure 1: World Merchandise Trade Volume, 2000-2022

Source: WTO Secretariat

IMF Managing Director Kristalina Georgieva pointed out that the year 2020 could see the worst global economic fallout since the Great Depression in the 1930s, with over 170 countries likely to experience negative per capita income growth due to the raging coronavirus pandemic.

\section{THE OECD PROGNOSIS OF THE WORLD ECONOMY}

All the countries will have to adopt increasingly stringent containment measures, needed to slow the spread of COVID-19 and according to the new OECD projections, this will necessarily lead to significant short-term declines in GDP for many major economies. In the process of preparation for the G20 Virtual Summit that took place on 25 March 2020, OECD Secretary General Angel Gurría brought to light the latest OECD estimations showing that the lockdown will directly affect various economic sectors amounting to up to one third of GDP in the major economies. The estimates reveal that for each month of containment, there will be a loss of 2 percentage points in annual GDP growth; the tourism sector alone faces an output decrease as high as 70\%. Many economies will fall into recession. 
In his statement at the G-20 Virtual Summit, Mr Gurría built on his recent call for a "Global Marshall Plan" to counteract the pandemic's effects. To "inoculate" economies to current and future shocks, he urged the G20 Leaders to act immediately, to:

- Recapitalise health and epidemiological systems;

- Mobilise all macro-economic levers: monetary, fiscal, and structural policies;

- Lift existing trade restrictions especially on much needed medical supplies;

- Provide support to vulnerable developing and low-income countries;

- Share and implement best practices to support workers and all individuals, employed and unemployed - particularly the most vulnerable;

- Keep businesses afloat, particularly small and medium-sized firms, with special support packages in hardest hit sectors such as tourism.

Mr Gurría emphasised that the impact on the annual GDP growth will, in the final analysis, depend on many factors, including the duration and magnitude of national shutdowns, the extent and severity of shunted or reduced demand for goods and services in other parts of the economy, and the momentum and speed at which significant fiscal and monetary support takes effect.

In all economies, the majority of this impact comes from the hit to output in retail and wholesale trade, and in professional and real estate services.

There are notable cross-country differences in some sectors, with closures of transport manufacturing relatively important in some countries, while the decline in tourist and leisure activities is relatively important in others.

The impact effect of business closures could result in reductions of $15 \%$ or more in the level of output throughout the advanced economies and major emerging-market economies; in the median economy, output would decline by $25 \%$.

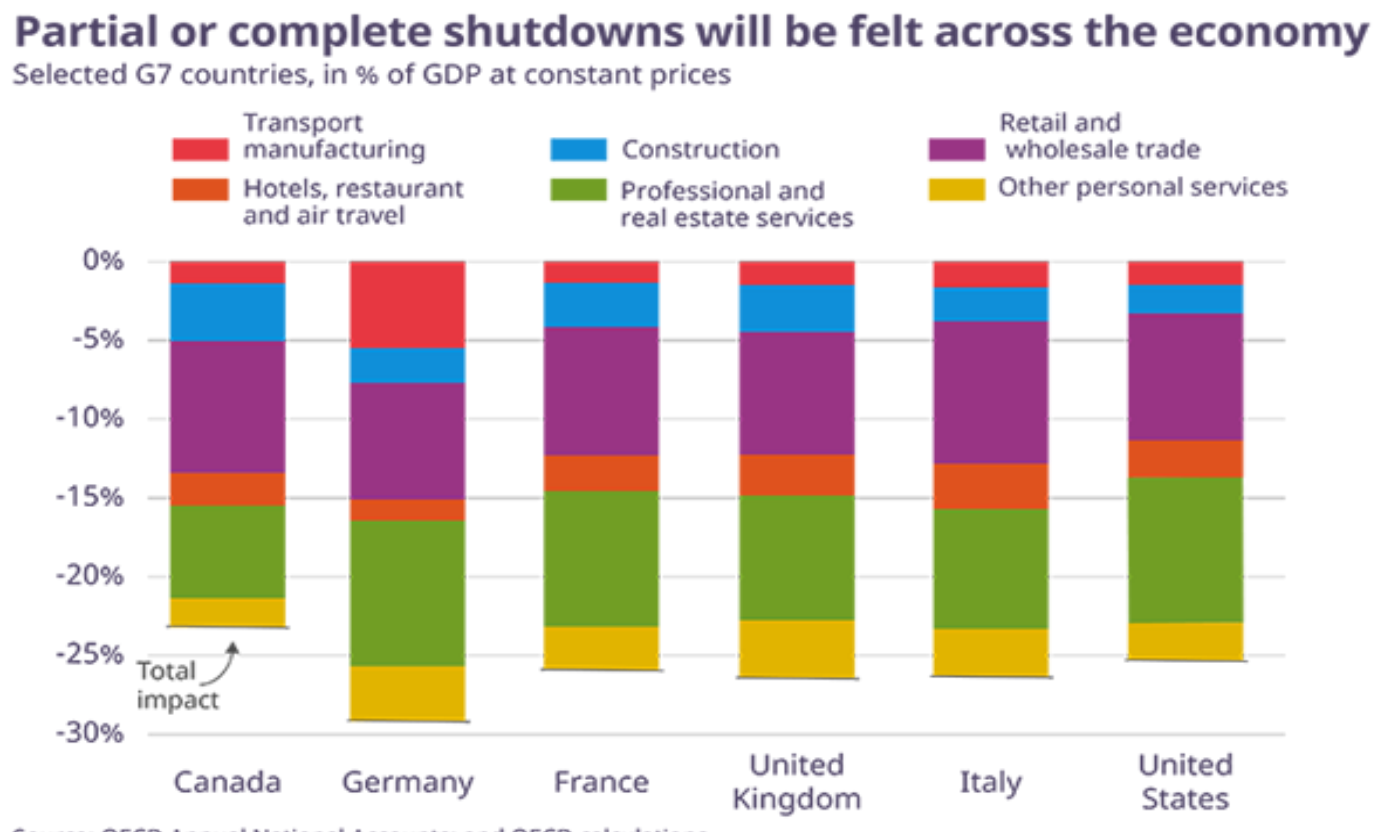

Source: OECD Annual National Accounts; and OECD calculations. 
Variations in the nature and magnitude of the impact across economies reflect differences in the composition of output. Many countries in which tourism sector is relatively more significant could potentially be affected more severely by limitations and shutdowns in travel. At the other extreme, countries with relatively sizeable agricultural and mining sectors, including oil production, may experience smaller initial effects from containment measures, although output will be subsequently hit by reduced global commodity demand. There will also be some variation in the timing of the initial impact on output across economies, reflecting differences in the timing and degree of containment measures; in China, the peak adverse impact on output is already past, with some shutdown measures now being eased.

The OECD has committed its expertise to support governments in developing effective policies in any sector necessary to slow the pandemic's spread and blunt its economic and societal effects from health, taxes, labour and employment to SMEs, education, science and technology, trade and investment and more.

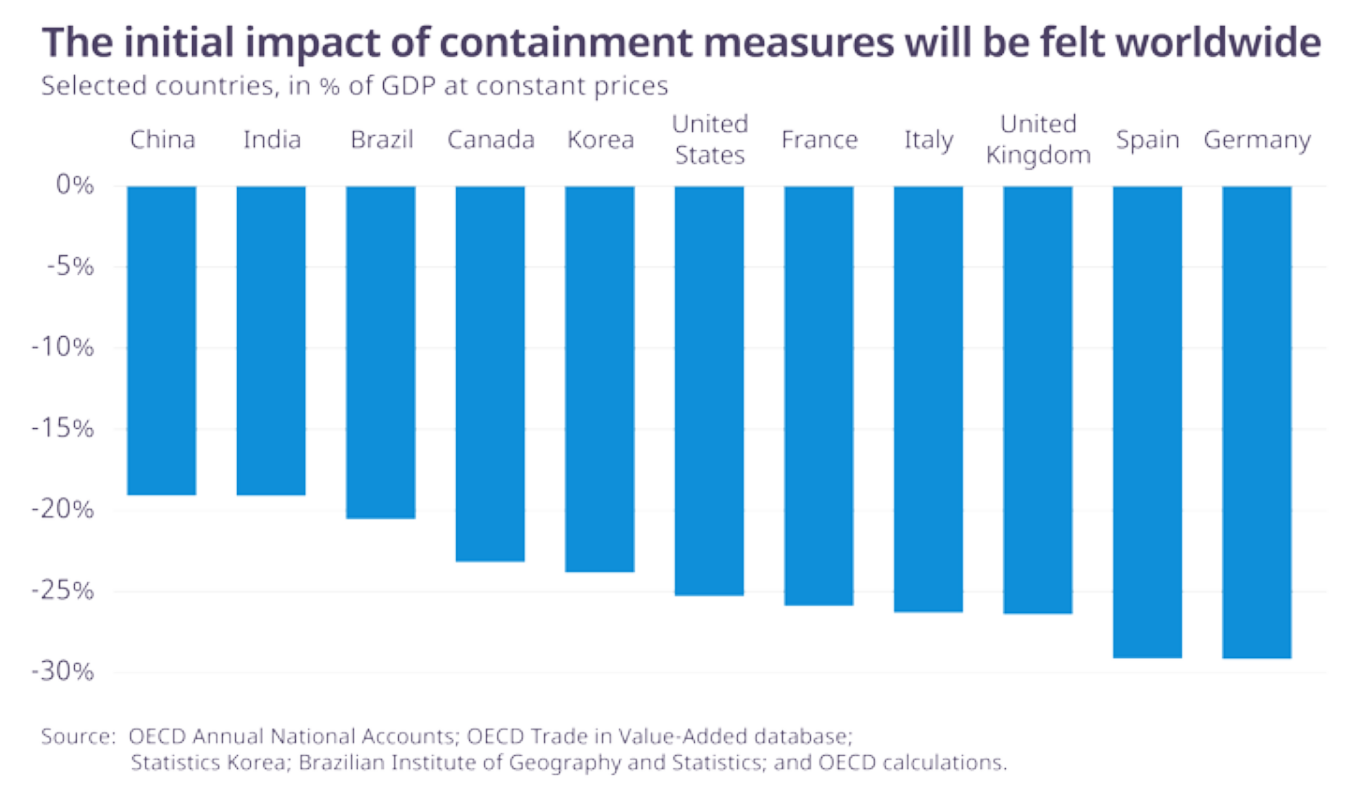

WORLD ECONOMY TREADING TOWARDS RECESSION

According to a new assessment from the UN trade and development body- UNCTAD, commodityrich exporting countries will face a $\$ 2$ trillion to $\$ 3$ trillion drop in investment from overseas in the next two years; an economic slowdown and in most cases an economic downturn in these emerging economies was already evident in the last quarter of the year 2019, which was before the new coronavirus outbreak emerged in central China last December. Many rich industrial nations have already announced a global rescue package plan amounting to $\$ 5$ trillion to provide an economic safety net of sorts to their businesses and workers; such an unprecedented measure should reduce the extent of their economic shock "physically, economically and psychologically." It is also expected to create $\$ 1$ trillion to $\$ 2$ trillion of demand among the major G20 economies, boosting global manufacturing by two per cent as was written in the latest UNCTAD report.

According to Richard Kozul-Wright, UNCTAD director of globalization and development strategies, the world economy will most likely move into a recessionary phase due to the onset of the 
coronavirus pandemic and its potential impacts with a predicted loss of global income in the trillions of dollars that will spell serious trouble for developing countries, with the exception of India and China; this was also reflected in the latest United Nations trade report.

As per the projections and estimations of UNCTAD, it is believed that part of the problem for most developing countries is that the backbone of their emerging economies is heavily dependent on informal workers working in unorganized sector; this amplifies their difficulties in responding to the crisis.

\section{Four-Point Recovery Plan}

Faced with a "a looming financial tsunami" of the current year, UNCTAD has developed a fourpronged strategy. This strategy initially calls for a $\$ 1$ trillion investment injection for weaker economies. UNCTAD's report elaborated that this injection would come from so-called "special drawing rights" governed by the International Monetary Fund (IMF) which would need to "go considerably beyond" the 2009 allocation made in response to the global financial crisis. The second measure is a debt freeze for distressed economies, involving an immediate standstill on sovereign debt payments, followed by significant debt relief. By way of example, UNCTAD cites how half of Germany's debt after World War Two, was cancelled. Based on this precedent, around \$1 trillion in debt should be cancelled this year, overseen by an independently created body, the UN agency maintains.

The third measure targets $\$ 500$ billion investment in poorer countries' emergency health services and related social relief programmes (\$500 billion Marshall Plan). Finally, UNCTAD urges the implementation of State-led capital controls to curtail already surging capital outflows from these developing countries. This would help to reduce a cash shortage driven by sell-offs in developing country markets and to arrest declines in currency values and asset prices.

\section{INTERNATIONAL ECONOMIC COOPERATION}

1. On 16 March 2020, the leaders of the G-7 countries (Canada, France, Germany, Italy, Japan, the United Kingdom, and the United States) held an emergency summit by teleconference to discuss and coordinate their policy responses to the economic fallout from the global spread of Covid19. In the joint statement released by the G-7 leaders after the emergency teleconference summit, the leaders stressed they are committed to doing "whatever is necessary to ensure a strong global response through closer cooperation and enhanced cooperation of efforts."

2. Saudi Arabia, the 2020 chair of the G-20, called an emergency Virtual G-20 Summit. During the global financial crisis, world leaders decided that henceforth the G-20 would be the premiere forum for international economic cooperation.

3. Analysts are hopeful that the recent G-7 summit, and movement towards a G-20 summit, will mark a shift towards greater international cooperation at the highest (leader) levels in combatting the economic fallout from the spread of Covid-19.

4. Some experts argue that a large, early, and coordinated response is needed to address the economic fallout from Covid-19, but several concerns loom about the G-20's ability to deliver. Their concerns are centred around the Trump Administration's prioritization of an "America First" foreign policy over one committed to multilateralism; Saudi Arabia is embroiled in its own domestic political issues and oil price war; and U.S.-China tensions make G-20 consensus more difficult. 
Ojha, S., \& Shubha. (2020) COVID-19: Anticipating A Dramatic Collapse and A Recessionary Phase In The World Economy. Archives of Business Research, 8(5). 1-7.

5. Apart from IMF and multilateral development banks, the Financial Stability Board (FSB), an international body that monitors the global financial system and makes regulations to ensure stability, released a statement on 20 March 2020 that its members are actively cooperating to maintain financial stability during market stress related to Covid-19.

\section{CONCLUSION: SOLUTIONS AND WAY FORWARD}

All countries must put in their best efforts to implement the four-point recovery plan as discussed previously. A recent innovative solution has come up in the form of a Global Hackathon which itself focuses on providing solutions to fight the COVID-19 pandemic. The core initiative comes from the Estonia based team from a start-up hackathon Garage48, government accelerator and a community-based platform for online innovation \& research, that organised a hackathon within six hours after the Government of Estonia had declared emergency in the country mid-March; the hackathon attracted people all over the world and the initiative grew global.

Under the umbrella of the global hackathon initiative, 53 regional hackathons have been conducted within less than a month, prior to the Global Hack; two hackathons were held in India: Fight Corona Ideathon and Hack the Crisis in India. The best teams from India amongst others includes chess grandmaster Garry Kasparov, entrepreneur, investor and strategist Reid Hoffman, astronaut Samantha Cristoferetti and actress Sophia Bush.

Apart from the above, several economic packages will be needed to support businesses, workers and healthcare systems engulfed by the crisis. Solutions like loan deferment and interest moratoriums represent a good start, but the situation necessitates deep structural solutions. As the world prepares to fight against COVID-19, every stakeholder needs to take steps to adjust and adapt to their new reality.

- Government- Certain measures include direct infusion/investments on the lines of Troubled Assets Relief Programme (TARP) targeted at specific sectors, infrastructure concessions, taxfree bonds, revisiting fiscal deficit targets, restructuring windows for businesses, land and labour reforms, etc.

- Lenders- Banks and NBFCs having significant exposure to badly hit industries such as hospitality, tourism, real estate, construction, infrastructure, etc. may need to review their portfolios, conduct diagnostics and work out 'sectoral relief packages'. The entire restructuring framework needs to be revisited. New structures/products at competitive pricing need to be thought through to support businesses that are backed by strong management.

- Promoters/Corporates- The current situation will require companies to assess short term liquidity to meet operational payments, re-evaluate and reassess their business strategies to adjust to the post-COVID scenario, make necessary adjustments to the capital structure, diversify funding sources, closely estimate cost structures to cut down excess expenditure, and explore potential disposals of non-core assets to optimise carrying costs and make balance sheets lean.

To sum up, the global nature of the pandemic, along with its great intensity and prolonged duration, will fundamentally alter the business landscape through changing trade flows, asset prices and consumption patterns. The need of the hour is to put in place a comprehensive action plan and put in the best efforts to implement the plan. 


\section{References:}

1. Prabir De, COVID-19, New Normal and India, (Economic Times, 9 April 2020), available at: https://economictimes.indiatimes.com/blogs/et-commentary/covid-19-new-normal-and-india/.

2. Trade Set to Plunge as COVID-19 Pandemic Upends Global Economy, (WTO 2020 Press Release, 8 April 2020), available at: https://www.wto.org/english/news_e/pres20_e/pr855_e.htm.

3. COVID-19: IMF anticipates sharply negative economic growth fallout since the Great Depression, (The Economic Times, 10 April 2020), available at: https://economictimes.indiatimes.com/news/economy-/indicators/covid19-imf-anticipates-sharply-negative-economic-growth-fallout-since-the-great-depression/-articleshow/75067158.cms.

4. New OECD Outlook on the Global Economy, (OECD.org, 26 March 2020), available at: https://www.oecd.org/coronavirus/en/

5. Angel Gurría's Statement at G20 Virtual Summit (25 March 2020), available at: https://read.oecd-ilibrary.org/view/?ref=126_126445-5ofyod1xpv\&title=ecretaryGeneralAngelGurriaStatementforthe-20-Video-conferenceSummitonCOVID19

6. \$2.5 Trillion COVID-19 Rescue Package Needed for World's Emerging Economies, (UN News, 30 March 2020), available at: https://news.un.org/en/story/2020/03/1060612.

7. Global Economic Effects of COVID-19, Congressional Research Service Report, R46270, https://crsreports.congress.gov/product/pdf/download/R/R46270/R46270.pdf/.

8. White House, G-7 Leaders' Statement, 16 March 2020, https://www.whitehouse.gov/briefings-statements/g7leaders-statement/.

9. Rebecca M. Nelson, The G-20 and International Economic Cooperation: Background and Implications for Congress, available at: https://fas.org/sgp/crs/row/R40977.pdf.

10. Jennifer Rankin, EU Leaders Divided on How to Protect Economies after Coronavirus, The Guardian.

11. Matthew Goodman and Mark Sobel, Time to Pull the G-20 Fire Bell, Center for Strategic and International Studies.

12. FSB Coordinates Financial Sector Work to Buttress the Economy in Response to Covid-19, Financial Stability Board, Press Release 6/2020.

13. Dipanjan Roy Chaudhury, India Joins Global Hackathon to Provide Solutions to COVID-19, available at: https://economictimes.indiatimes.com/small-biz/startups/newsbuzz/india-joins-global-hackathon-to-providesolutions-to-covid-19/articleshow/75084744.cms?utm_source=contentofinterest-\&utm_medium=text-\&utmcampaign=cppst.

14. Navigating the COVID-19 crisis: avoiding debt defaults and insolvencies as a 'new normal' emerges, KPMG International Cooperative, available at: https://home.kpmg/in/en/home/insights/2020/04/navigating-thecovid-19-crisis.html 